\title{
THE BENEFITS OF COOPERATION BETWEEN INDUSTRY AND UNIVERSITIES
}

The importance of business partners for universities can be documented using the example of the "Center for Business Information Management and Technology" (CBI) at ZHAW. The quality of the collaboration is determined by the size of the university's organizational unit, the interdisciplinary network, the experience, competence and skills of the faculty, and the neutrality of the university. However, the business partner should play a role in all four main activities in which the university unit is involved:

- for the undergraduate and graduate programs, the business partner may be responsible for specific lectures (like presenting a business case);

- for continuous education, the business partner may organize excursions in addition to specific lectures (such as a study trip to India);

- for consulting projects, the business partner may involve faculty of the university; and

- for applied R\&D projects, the business partner may provide employees with special skills and competencies.

It is a challenge for the faculty to balance all four of these activities. For example, one cannot spend more than 30\% of working hours lecturing. It turned out that a major drawback for sustainable growth is the lack of sales skills in the faculty. Obviously, research and sales skills are conflicting. One solution is the right choice of business model, which in our case, is collaboration with consultancy enterprises rather than with end customers.

The long-term relation with our business partners is based on mutual benefit. Stefan Metzger, CEO of Cognizant Switzerland, witnessed this. He is one of our business partners experiencing the win-win-situation of such collaboration for many years. While young students apply their knowledge in business cases given by the industry partner, he gets innovative and creative solutions from them. Furthermore, the need for new employees can be met more easily despite the existing war for talents.

Author

Prof. Dr. Thomas Keller

Head of the Center for Business Information Management and Technology School of Management and Law at Zurich University for Applied Sciences Stadthausstrasse 14, CH-8401 Winterthur th.keller@zhaw.ch 